\title{
EL COMERCIO INTERNACIONAL DE PRODUCTOS AGRÍCOLAS EN LOS OCHENTA Y LAS CONSECUENCIAS PARA MÉXICO
}

\author{
por \\ Carlos Vidali*
}

\section{RESUMEN}

El trabajo tiene como propósito analizar la evolución reciente y las tendencias del comercio agropecuario, las políticas de subsidios a la producción y exportación de los parses desarrollados, el impacto de estas políticas en el tercer mundo y los planteamientos y negociaciones en el seno del GATT para intentar el planteamiento de opciones productivas para los paises en desarrollo y en particular para México.

\begin{abstract}
The purpose of this study is to analize the recent development and tendencies of the agricultural commerce, the allowance policy of the developed countries towards production and exportation, the impact of these policies over the third world and the layout and negotiation in the botom of the GATT, as an attempt to set forth productive options for the developing countries and particularly for Mexico.
\end{abstract}

\section{INTRODUCCIÓN}

La agricultura es una de las actividades humanas más antiguas, sus productos se destinan - directa o indirectamente- a la alimentación humana y son fuente importante de empleo. Es y seguirá siendo una actividad de importancia indiscutible a pesar de su bajo peso relativo en el producto interno bruto; ello explica por qué todos los países están comprometidos en el fomento de la producción agropecuaria y en su protección.

El propósito de satisfacer la demanda alimentaria, evitar el hambre y la desnutrición significa producir más alimentos y controlar la dependencia del exterior. Esta posición considera el intercambio comercial con el exterior, pero establece que dichos intercambios deben ser equilibrados y que no impliquen una dependencia unilateral.

- Vicepresidente general ejecutivo de Ocean Garden Products, Inc. en San Diego, California. De 1984 a 1989 ocupo el cargo de director general de Asuntos Internacionales de la Sría. de Agricultura y Recursos Hidráulicos. 
En este sentido, la política agropecuaria forma parte de la política de desarrollo y también de la estrategia global de seguridad nacional. El desenvolvimiento agrícola de los ochenta — sobreproducción subsidiada en países desarrollados alternada con carencias en las naciones menos desarrolladas-, el incremento del proteccionismo, la inestabilidad de los precios combinados con agudos problemas financieros, han sido sin duda las limitaciones reales de la agricultura en el periodo.

Por otro lado, a pesar de los importantes progresos científicos y tecnológicos que se han producido - sobre todo las innovaciones biotecnológicas y la ingeniería genética-, la producción agropecuaria de los países en desarrollo y aún en los desarrollados todavía sigue dependiendo en buena medida de condiciones naturales de clima, suelo, ubicación geográfica y del impulso que los gobiernos otorgan mediante programas de apoyo, dotación de infraestructura, financiamiento, etc.

El presente trabajo tiene como propósito analizar la evolución reciente y las tendencias del comercio agropecuario, las políticas de subsidios a la producción y exportación de los países desarrollados, el impacto de estas políticas en el tercer mundo y los planteamientos y negociaciones en el seno del GATT para intentar el planteamiento de opciones productivas para los países en desarrollo y en particular para México.

\section{EVOLUCIÓN RECIENTE Y TENDENCIAS DEL COMERCIO AGROPECUARIO}

El comercio agrícola internacional de los últimos años se caracteriza por dos hechos relevantes: 1) una participación cada vez menor en el comercio global y 2) el incremento de las fricciones con que se realiza.

El descenso de la participación de la agricultura en el comercio internacional forma parte de las transformaciones de la economía mundial, cuyo razgo más evidente es la modificación de las estructuras productivas. Como señala Peter Drucker (1987:38):

"la economía de productos primarios se ha desligado de la industrial, ésta a su vez se ha desvinculado del empleo, y el flujo de capitales, más que el del comercio, parece constituir la fuerza motriz de la economía mundial".

El menor peso de la producción de bienes primarios es un fenómeno complejo y a la vez paradójico. Complejo porque en términos absolutos el mercado mundial de productos agropecuarios se ha expandido a razón de $7 \%$ promedio entre 1950 y 1987, pasando de 28 mil millones de dólares en 1950 a 325 mil millones en 1987, es decir, se ha multiplicado más de once 
veces. La revolución verde, estrategia que pretendía acabar con el hambre aumentando la producción, aunque no logró lo primero (porque es más complejo que incrementar la oferta), consiguió lo segundo, al obtener solamente aumentos significativos en la productividad, sobre la base de paquetes tecnológicos integrados por fertilizantes, semillas mejoradas, maquinaria, etc., que es un paquete costoso aún para los países desarrollados.

La revolución en la ingeniería genética ha logrado aumentos sustanciales en la productividad del trigo, maíz, producción de proteína, unicelular, azúcar del maguey entre otras cosas. La paradoja se presenta porque la sobreproducción se ha generado donde no hace falta, y donde es necesario la producción ha entrado en crisis: abundancia y carencia simultáneas. Para decirlo pronto, no es que haya habido un descenso en la producción agrícola, sino que el ritmo de crecimiento de ésta ha sido inferior al de las manufacturas, donde el impacto de la revolución científico-tecnológica ha sido superior. El descenso de largo plazo en la participación de la agricultura en el producto total se da en términos de valor mas no de volumen, como resultado de una tendencia a la baja de los precios en relación con el precio de las manufacturas. Estos precios, además de bajar son muy inestables, la gráfica de los precios de las materias primas agrícolas se asemeja al encefalograma de un loco.

Las fluctuaciones de los precios y materias primas agrícolas son efecto de variaciones importantes en la oferta, producidas por políticas de fomento a la producción; por la competencia de sucedáneos que desplazan a los naturales del mercado y también de las fluctuaciones del valor de las monedas locales frente al dólar, divisa en la cual se realiza la mayor parte de las cotizaciones internacionales de los productos agrícolas. La estabilidad de los precios es uno de los principales problemas del comercio agropecuario, pues si bien en el decenio de los setenta se lograron promediar aumentos sustantivos, en los ochenta han bajado de manera drástica, con fuertes oscilaciones, hasta llegar en términos reales a los niveles previos a la segunda posguerra. La sobreoferta generó acumulación de excedentes que no se han podido distribuir, originando serios problemas financieros y de regulación en el uso de los recursos naturales.

Estos excedentes de producción son en gran parte resultado del estímulo y la protección agrícola de los principales países industrializados; políticas que exceden con mucho el ámbito agropecuario, pues tienen que ver con los significativos cambios de la política económica general y con las profundas reestructuraciones tanto de la economía general como reestructuración de la economía internacional. Ciertamente también ha influido la contracción de las importaciones de los países subdesarrollados, obligada por su carencia de recursos financieros. 
A manera de ejemplo, la producción de trigo aumentó $69 \%$ en los ochenta mientras los precios bajaron $45 \%$; los precios del azúcar estaban en 1988 a un nivel $85 \%$ inferior al de 1980, por un acelerado proceso de cambio tecnológico, mientras las reservas subían $45 \%$. Algo similar puede decirse de la leche, la mantequilla y las carnes.

Esta sobreoferta no hubiera sido posible sin la enorme cantidad de recursos financieros orientados al fomento de la producción y las exportaciones. Sólo en 1987 Estados Unidos destinó 30 millones de dólares a subsidiar la agricultura, cifra equivalente al $15 \%$ de su déficit comercial. A esa cantidad se agregaron de 5 a 6 mil millones de dólares debido a precios administrados en niveles superiores a los del mercado internacional, como el azúcar y algunos lácteos.

La Comunidad Económica Europea (CEE) también destina montos considerables a subsidiar la agricultura, mediante su Política Agrícola Común (PAC). Se calcula que en el año agrícola 1986-1987 los subsidios directos ascendieron a 25 mil millones de dólares, a lo que habría que agregar los costos financieros que originan los excedentes. En Japón el arroz se paga a un precio equivalente a ocho veces el precio del mercado internacional. Las cifras agregadas de subsidios japoneses se calculan en más de 22 mil millones de dólares; pese a ello, los productores sufren severos problemas financieros y las quiebras de granjeros continúan a tasas sin precedentes en la historia.

Sin embargo, conviene enfatizar que las dificultades que atraviesa la agricultura a escala internacional, no se deben a las políticas en sí mismas, sino a la desfavorable interacción en dichas políticas con las macroeconómicas y las financieras en particular, esto aunado al sensible descenso de la demanda, los problemas de endeudamiento del tercer mundo y la atonía económica mundial.

En la CEE el efecto de los subsidios en el ingreso nacional y el empleo es considerable, algunos cálculos señalan que al menos un millón de desempleos tienen que ver directamente con quiebras y problemas agrícolas.

La Política Agrícola Común (PAC) de la CEE (establecida mediante el artículo 39 del Tratado de Roma) se propuso como objetivos principales aumentar la productividad agrícola, asegurar un nivel de vida equitativo para la población dedicada a la agricultura, estabilizar los mercados y garantizar la disponibilidad de alimentos a precios razonables a los consumidores. El análisis de la PAC, sin embargo, muestra que la realización simultánea de esos objetivos es necesariamente conflictiva, ya que se trata de una forma de intervención múltiple en los mercados, que si bien ha tenido éxito para aumentar la productividad y lograr mejores ingresos para los agricultores, ha sido onerosa en el largo plazo. El principio central de 
la PAC son precios comunes para los productores de la comunidad superiores a los externos y financiamiento agrícola centralizado.

Los precios comunes para los doce miembros significa que, dada la disparidad de tamaño, productividad, tecnología y estructura productiva, se genera una renta diferencial a favor de los productores más eficientes, lo que no ha dejado de crear dificultades. El aislamiento del mercado comunitario del externo se logra mediante impuestos variables ("variable levy") determinados por la diferencia entre el precio internacional de oferta más bajo para el producto en cuestión y un precio interno políticamente determinado, llamado precio de referencia (target price). Los precios de referencia se fijan a niveles superiores a los del mercado mundial, por lo que crearon un mecanismo para restituir a los exportadores la diferencia entre los elevados precios internos y los de mercado exterior.

En los hechos, los impuestos variables aislaron a la CEE de las fuerzas del mercado mundial, lo cual no era tan grave cuando la comunidad era un importador neto, pero a partir de los setenta, la inversión acelerada incrementó la productividad y la producción frente a una demanda doméstica estancada, y en menos de una década la CEE pasó a ser un formidable exportador de granos, azúcar, carne vacuna y pollo, mientras las importaciones agropecuarias bajaron. Sin embargo, a medida que los costos financieros aumentaron por la acumulación de excedente, la CEE tuvo que desarrollar mecanismos de intervención en los precios internos a fin de amortizar la baja a medida que las reservas aumentaban, situación agravada por la devaluación de las monedas europeas frente al dólar. La situación llegó a tal grado que, en 1985 y 1986, la comisión tuvo que recomendar recortes, aunque modestos, en algunos precios de referencia, sin que ello significara cambios importantes en la política agrícola común a pesar de las presiones internas y externas (Luiselli y Vidali:1989).

Los elementos centrales de la política agrícola de Estados Unidos (establecidos desde hace cincuenta años en la época de New Deal) son: precios de garantía o de apoyo al productor; control de la producción con mecanismos de compensación fiscal —que incluyen incluso la reducción de áreas de cultivo y sacrificio de ganado sobrante- y subsidios o compensaciones cuando los precios internos sean sensiblemente inferiores al precio objetivo, definido éste como el requerido para mantener estables los ingresos de los granjeros.

Los precios de apoyo, en la práctica, fueron desplazados por los subsidios a la exportación, al tiempo que se impusieron cuotas a la importación agropecuaria. En los sesenta, los precios de compensación y el programa de disminución de la superficie sembrada redujeron los subsidios, hasta que a principios de los setenta el "boom" exportador, 
mezcla de reacción al alza generalizada de los precios y a un dólar artificialmente barato, relajó los controles de la superficie cosechada ${ }^{1}$.

Las malas cosechas de la Unión Soviética, el favorable tipo de cambio y el crecimiento elevado de algunos países del tercer mundo hicieron que todo el decenio de los setenta hasta 1981 fuera de incremento de las exportaciones, en particular de trigo, maíz, soya y otros cereales. Los precios internacionales permitieron un bajo costo fiscal. Sin embargo, los importantes cambios de la economía mundial de principio de los ochenta modificaron sustancialmente el panorama. La recesión de la mayor parte de los países en desarrollo, el alza de las tasas de interés, la adopción de tipos de cambio administrados y la baja como tendencia de los precios de las materias primas y productos agrícolas tuvieron serias repercusiones en el comercio agropecuario, cuya concentración entre países desarrollados se acentúo aún más (cuadro 1).

En 1983, Estados Unidos estableció un agresivo programa de retiro masivo de tierras del cultivo, mediante un esquema conocido como PIK, que no es otro cosa más que un pago relativo al valor de los excedentes. Los precios no sólo declinaron, sino también el valor de las tierras y de los activos en momentos en que las tasas de interés real crecían, dejando a un gran número de granjas sin capacidad de pago. Para mediados de los ochenta la agricultura norteamericana ya estaba en su más profunda crisis desde la gran depresión, con innumerables bancarrotas y una acelerada tendencia a la concentración de la propiedad agrícola.

Para evitar dificultades, el Congreso de los Estados Unidos, junto con los granjeros, instrumentó un programa de subsidios al tiempo que restringía el gasto público destinado a la agricultura. El incremento de los subsidios, combinado con la elevada productividad de las tierras norteamericanas, aumentó las ventas al exterior, desplazando del mercado internacional a productores naturales como Argentina, Australia, Canadá y otros que, más adelante en el GATT, se agruparían en el llamado grupo Cairns. Destaca la enorme producción de Estados Unidos de azúcar, carne, maíz, trigo, lácteos, soya entre otros. Con sus clarísimas ventajas naturales, de capital y tecnológicas, Estados Unidos será siempre un país de grandes posibilidades productivas sobre todo de cereales y lácteos (Véase cuadro 1).

En contraste con las políticas de fomento a las exportaciones de los países desarrollados, destaca la atonía agrícola de las naciones en desarro1lo. Es importante señalar que la crisis agrícola de estos países rebasa al

1 En 1955 Estados Unidos logró un "waiver" o exención en las reglas del GATT —que prohíben restringir las importaciones- $-\infty$ el cual han protegido su agricultura y la mantienen al margen del Acuerdo. 
CUADRO 1. Situación mundial de los cereales (Millones de toneladas)

\section{$\begin{array}{llllll}\text { Concepto } & \mathbf{8 4 - 8 5} & \mathbf{8 5 - 8 6} & \mathbf{8 6 - 8 7} & \mathbf{8 7 - 8 8} & \mathbf{8 8 - 8 9}\end{array}$}

Producción

$\begin{array}{llllll}\text { Total de cereales } \quad 1805 & 1842 & 1863 & 1798 & 1730\end{array}$

$\begin{array}{llllll}\text { Países en desarrollo } & 921 & 925 & 943 & 930 & 958\end{array}$

$\begin{array}{llllll}\text { Países desarrollados } & 884 & 917 & 920 & 868 & 772\end{array}$

Importaciones mundiales

Total de cereales

$\begin{array}{lllll}217 & 181 & 188 & 198 & 199\end{array}$

$\begin{array}{llllll}\text { Países en desarrollo } & 109 & 99 & 111 & 116 & 120\end{array}$

$\begin{array}{llllll}\text { Países desarrollados } & 108 & 82 & 78 & 82 & 79\end{array}$

Existencias mundiales (1)

Arroz (elaborado)

54

55

51

39

36

Trigo

152

$160 \quad 168$

146

120

Cereales secundarios

129

205

$230 \quad 211$

121

Total de cereales

335

420

$449 \quad 396$

277

Países en desarrollo

137

132

132

118

112

Países desarrollados

198

288

317

278

165

Existencias como \% del consumo

FUENTE: Perspectivas Alimenticias. FAO. Nov., 1988.

(1) Las cifras se basan en un agregado de los niveles nacionales de remanentes al final de los años agrícolas nacionales.

sector, al originarse primero en las políticas de industrialización y después en las de estabilización y ajuste estructural, así como en el exhorbitante peso del servicio de la deuda. Es decir que la situación de la agricultura se relaciona directamente con el papel del Estado y el marco internacional, de ahí que la corrección de los desequilibrios agrícolas sea tan compleja.

Para América Latina la situación ha significado el sometimiento a mercados tremendamente inestables, nuevas relaciones de dependencia en 
condiciones de un enorme endeudamiento externo y excedentes baratos para los programas de ayuda alimentaria a los países más pobres (con un cierto tinte político).

Las distorsiones agrícolas no afectan al conjunto de los productores agropecuarios, sino a un número relativamente reducido de éstos, cuya importancia está en función del papel que dichos productos tienen en la dieta regional. Entre estos productos destacan cereales como el maíz y el trigo; oleaginosas, como semillas y aceite de soya; carne vacuna; lácteos y azúcar, productos equivalentes al 58\% del aporte en calorías y el $56 \%$ de las proteínas de la dieta alimentaria latinoamericana (Chibbaro:1988).

Los productos en los que América Latina es tradicionalmente exportador, como los productos tropicales (azúcar, café, algodón, cacao, banano) tienen en peso específico bajo en las distorsiones de mercado agrícola mundial, dominado por los cereales, los lácteos y las carnes. Sin embargo, también se ven enfrentados a una situación de precios y mercados profundamente inestables, debido a que no son productos indispensables en la alimentación, fácilmente sustituibles por sucedáneos y escasamente integrados a procesos de transformación en los países exportadores.

\section{CUADRO 2. Precios de algunas exportaciones (dólares/tonelada)}

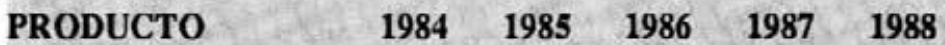

Café (oIc 1979, precio

diario)

Cacao (пCO, precio

diario)

Azúcar (CIA, precio

diario)

Yute (BWC job C.

Chalma)

Té (Londres, todos

los tés) $\begin{array}{lllll}3108 & 2942 & 3768 & 2379 & 2596\end{array}$

$\begin{array}{lllll}2398 & 2241 & 2068 & 1997 & 1637\end{array}$

$\begin{array}{lllll}115 & 90 & 133 & 148 & 220\end{array}$

$\begin{array}{lllll}541 & 613 & 326 & 389 & 440\end{array}$

$\begin{array}{lllll}3500 & 2014 & 1930 & 1688 & 1762\end{array}$

FUENTE: Elaborado con base en datos aparecidos en: SOUTH a third world magazine.

De América Latina, los países importadores de alimentos más destacados en volumen y valor son México, Venezuela, Brasil, Perú, Colombia, 
América Central y el Caribe. Para estos países, la baja de los precios de los productos agrícolas importados (efecto de los excedentes) ha tenido efectos favorables en el corto plazo, al permitir el acceso a alimentos más baratos (aunque no es raro que los intermediarios se apropien del diferencial) y un cierto respiro en la balanza comercial. (Véase cuadro 3).

CUADRO 3. América latina. Importaciones de alimentos promedio 1983-1985

(millones de dólares)

\begin{tabular}{|c|c|c|c|c|c|}
\hline País & $\begin{array}{l}\text { Animales } \\
\text { vivos y } \\
\text { carne }\end{array}$ & Cereales & $\begin{array}{l}\text { Productos } \\
\text { lácteos }\end{array}$ & $\begin{array}{l}\text { Aceites } \\
\text { animales } \\
\text { y vegeta- } \\
\text { les }\end{array}$ & Total \\
\hline Bolivia & (2.5) & 70.6 & 8.2 & 8.8 & 85.1 \\
\hline Brasil & (804.1) & 918.2 & 21.4 & (674.4) & (538.9) \\
\hline Chile & 3.3 & 147.8 & 18.4 & 62.2 & 213.7 \\
\hline Colombia & (6.7) & 161.6 & 8.9 & 77.3 & 241.1 \\
\hline Cuba & 114.7 & 442.3 & 90.2 & 82.4 & 729.6 \\
\hline República & & & & & \\
\hline Dominicana & (1.9) & 62.6 & 14.2 & 40.0 & 114.9 \\
\hline Ecuador & 5.9 & 65.5 & 5.4 & 38.3 & 115.1 \\
\hline Jamaica & 22.5 & 85.8 & 23.0 & 15.9 & 147.2 \\
\hline México & 13.7 & 648.2 & 150.7 & 132.3 & 944.9 \\
\hline Perú & 18.4 & 190.2 & 40.2 & 37.0 & 285.8 \\
\hline Trinidad & & & & & \\
\hline y Tobago & 51.2 & 75.7 & 61.2 & 19.5 & 207.6 \\
\hline Venezuela & 30.0 & 476.0 & 131.2 & 193.3 & 830.5 \\
\hline $\begin{array}{l}\text { América } \\
\text { Latina y }\end{array}$ & & & & & \\
\hline Caribe & 503.7 & 3740.7 & 770.7 & 854.8 & 5869.9 \\
\hline Totales & (51.8) & 7085.2 & 1343.7 & 887.4 & 9264.5 \\
\hline
\end{tabular}

FUENTE: Elaborado con base en cálculos de la UNCTAD.

() Exportaciones

Considera importaciones netas (importaciones menos exportaciones).

Para el largo plazo, por el contrario, la situación ha influido en la adopción de una estructura productiva volcada a la veleidad del mercado 
internacional con su consecuente inseguridad en los precios y dependencia en el abasto externo. La actividad agropecuaria de muchos de estos países se ha desincentivado con consecuencias adversas en el empleo, el desarrollo rural y la balanza de pagos. Por otro lado, Estados Unidos, seguido a distancia por la Comunidad Económica Europea, se han convertido en los principales abastecedores de los países latinoamericanos y habida cuenta de su política proteccionista, no resulta aconsejable depender estructuralmente de ellos para satisfacer la demanda del mercado interno.

Ciertamente que en los dos últimos affos la producción de cereales ha disminuido. La producción mundial de trigo paso de 538 millones de toneladas en 1987 a 511 millones (estimados) en 1988, baja de 5\%. Los cereales secundarios, donde la reducción fue mayor, pasaron de 853 millones de toneladas en 1986 a 741 millones en 1988. La producción de arroz en cambio aumentó. El efecto principal de la disminución de la producción se registro en las existencias, que bajaron de 449 millones de dólares a 277 millones en el mismo periodo, es decir, que hubo una reducción de $30 \%$, no experimentada desde hace 40 años, nivel inferior al mínimo indispensable para garantizar la seguridad alimentaria mundial.

Según la FAO, las reservas mínimas para garantizar dicho nivel deben corresponder al $18 \%$ del consumo anual, y ahora se encuentran aproximadamente al $16 \%$, primera vez que sucede desde la crisis alimentaria mundial de principios de los affos setenta (FAO:1988).

El descenso de la producción se debe a varias razones, en los países desarrollados y en especial en Estados Unidos es resultado de los programas que con dicho objetivo se han instrumentado (retiro de tierras del cultivo y sacrificio de vacas y de la fuerte sequía de 1988). En la Unión Soviética, los rendimientos de la parte oriental bajaron por la sequía; en la República Democrática Alemana, Polonia y Rumania las cosechas fueron inferiores, quizá por fallas en la planeación, en cambio aumentaron en Europa Occidental. En los países subdesarrollados el descenso se debió a catástrofes naturales, ciclones en América Central, sequías y plagas en Africa, e inundaciones en el sureste de Asia (cuadro 4).

Sin embargo, este descenso en la producción agrícola no puede considerarse como un cambio en la tendencia, ni siquiera en el caso de Estados Unidos, sino como un ajuste coyuntural provocado por fenómenos naturales en la mayor parte de los países. En Estados Unidos la incorporación inmediata de las innovaciones genéticas y biotecnológicas se expresan en incrementos constantes en la productividad, acompañados de reducción en los costos, lo cual aparece también como tendencia. En esta perspectiva . no es posible afirmar la viabilidad de modificaciones importantes en la tendencia. Ejemplo de ello es la falta de acuerdo entre Estados Unidos y 
CUADRO 4. Participación de la agricultura en el producto interno bruto y en empleo (porcentajes)

AGRICULTURA/PIB AGRICULTURA/(EMPLEO) $\begin{array}{llll}1965 & 1985 & 1965 & 1985\end{array}$

Países en

desarrollo

29

20

70

62

Países

desarrollados

5

3

14

FUENTE: GATT. El comercio internacional 1987-1988. Anticipo editorial.

la Comunidad Económica Europea respecto a las reformas de comercio agrícola mundial.

\section{LIBRE CAMBIO VS. PROTECCIONISMO}

A los problemas y tendencias del comercio y la producción hay que agregar los derivados de las políticas proteccionistas, en particular de los países desarrollados, destinados a proteger los ingresos de sus agricultores y elevar el grado de autosuficiencia, aislando el mercado interno del externo. Esta situación explica la desviación cada vez mayor (como apuntabamos antes) del comercio agrícola respecto al de manufacturas.

Sobre el proteccionismo de Estados Unidos, que es el que más nos interesa por ser con mucho el principal socio comercial, conviene aclarar varias cosas. En primer lugar, existe cierta tendencia de ver a Estados Unidos como si fuera una unidad comercial que protege de la misma manera sus compras de verduras frescas que las de vestidos o de productos siderúrgicos. En segundo, la inclusión o eliminación de los productos extranjeros en el Sistema Generalizado de Preferencias (SGP) de ese país no necesariamente significa apertura o proteccionismo, pues varios productos han sido excluidos del SGP a cambio de bajarles o eliminarles los aranceles. No ha sido con proteccionismo que las exportaciones de productos textiles de los países en desarrollo a Estados Unidos aumentaron en su participación en la industria textil de este país de 3.4\% a $15 \%$ entre 1970 
y 1980, como señala un estudio del Banco Mundial. La cerveza mexicana, cuando perdió el trato preferencial que tenía, incrementó sus ventas sustancialmente. ${ }^{2}$

En tercer lugar, hay que considerar la variable política, ya que en el país "operan" fuerzas políticas y/o comerciales a favor o en contra del proteccionismo en áreas o productos específicos. En el caso de las agroexportaciones mexicanas, la situación es bastante clara. El triunfo mismo del equipo conservador en la presidencia contó, entre los apoyos que tuvo, el de los granjeros cuya actitud hacia las importaciones mexicanas de hortalizas frescas es bien conocida.

Los agricultores de Florida, ante el "boom" de las importaciones de frutas y hortalizas mexicanas, han expresado varias veces que no están dispuestos a que el gobierno de Estados Unidos los convierta en el "cordero del sacrificio" por los intereses políticos de su país respecto a México. Estos agricultores se quejan de que los productos mexicanos han incrementado sus ventas en Estados Unidos por los bajos costos mexicanos, mientras que los exportadores mexicanos acusan al Departamento de Agricultura de ese país de ejercer barreras proteccionistas mediante normas técnicas y fitosanitarias. La guerra del tomate es un ejemplo claro (cuadro 5).

Evidentemente el problema del proteccionismo remite a las necesidades específicas de cada país; así, mientras Estados Unidos alienta sus exportaciones de cereales, lácteos y oleaginosas, impone restricciones a las importaciones de frutas y verduras y sobre todo en las épocas del año en que tiene abundante producción nacional. México en cambio impulsa las exportaciones de hortalizas, frutas y flores, y en cambio protege, mediante permisos de importación y control estatal de las compras, las importaciones de cereales, lácteos y oleaginosas. A primera vista pareciera que ambos sectores agrícolas se complementan, pues mientras en uno sobra maíz en el otro falta y en éste hay excedentes de hortalizas en invierno que no crecen en el primero; por lo tanto, lo único que aparece como necesario es adecuar los volúmenes de producción a las necesidades ajenas, ya que la fuente de conflicto son los excedentes. Sin embargo, la realidad es más compleja, por lo que no puede resolverse sólo con un criterio de pragmatismo contable. Por un lado está el asunto de las ventajas comparativas, los excedentes no son casuales, son expresión justamente de dichas ventajas, pero por otro, están las cuestiones de seguridad nacional y desarrollo rural.

2 Véase: Economic Report of the President. Goverment of the United States, Washington, 1987. América Latina-Estados Unidos: evolución de las relaciones económicas. SBLA, Sigio XXI editores, México, 1986. 
CUADRO 5. Exportaciones agropecuarias y forestales de México a Estados Unidos (millones de dólares)

\begin{tabular}{cccc}
\hline Año & $\begin{array}{c}\text { Exportaciones totales } \\
\text { A }\end{array}$ & $\begin{array}{c}\text { Exportaciones a EUA } \\
\text { B }\end{array}$ & $\begin{array}{c}\text { Participación } \\
\text { B en A } \\
\%\end{array}$ \\
\hline & & & \\
1980 & 1844 & 1157 & 62.7 \\
1981 & 1677 & 1157 & 69.4 \\
1982 & 1264 & 658 & 52.1 \\
1983 & 1714 & 751 & 43.8 \\
1984 & 1760 & 1024 & 58.2 \\
1985 & 1517 & 950 & 62.6 \\
1986 & 2414 & 1845 & 76.5 \\
1987 & 2183 & 1837 & 84.1 \\
\hline
\end{tabular}

FUENTE: Secretaría de Hacienda y Crédito Público.

México no puede eliminar los permisos de importación a los productos básicos sólo por razones de índole agropecuaria, sino que tiene que considerar razones de Estado. Por su parte, los Estados Unidos tienen que recurrir a una ley comercial proteccionista, por el elevado peso de su déficit comercial en las cuentas nacionales, razón de estado también. La articulación comercial entre ambos países es prioridad para las dos administraciones, pero está evidentemente subordinada a consideraciones macroeconómicas y a políticas internas determinadas por los intereses nacionales respectivos.

El ingreso de México al GATT tuvo entre otros propósitos, el de "desbilateralizar" sus relaciones comerciales; mientras la Conferencia de la Cuenca del Pacífico constituye para Estados Unidos la posibilidad de diversificar el origen de sus compras agropecuarias.

En Estados Unidos, paladín del libre comercio en otra época, la idea de crear una economfa-locomotora por encima de la competencia europea o japonesa requirió financiamiento de todos lados, para conseguirlo elevó las tasas de interés y devaluó el dólar, con esta política se convirtió en una esponja que absorbía capitales de todo el mundo. El precio de esa política fue el desaliento a las ventas externas y el estímulo a las importaciones, con un efecto directo sobre su balanza comercial. Fue asf que el sector 
externo se volvió vulnerable y Reagan tuvo que encarecer el dólar y restringir las importaciones recurriendo al proteccionismo.

México en cambio, deseoso de crear una planta productiva propia, fuerte, dinámica y volcada al mercado interno, se protegió de la producción externa, estrategia que fracasó relativamente, dejando profundas huellas en el aparato productivo. El gobierno entonces tuvo que recurrir a la racionalización de la protección y la consiguiente apertura al exterior como parte de una nueva estrategia de desarrollo para favorecer la modernización.

Al parecer, las políticas de desarrollo de ambos países están desfasadas, pues mientras México impulsa decididamente la liberalización de su sector externo para modernizarse, Estados Unidos los cierra parcialmente para corregir sus problemas de balanza de pagos. Lo cierto es que ambos países se encuentran en la actualidad frente a la necesidad de reformular su política de comercio exterior, tanto en términos de mercados como de productos.

Además el libre comercio no puede entenderse ni aplicarse como dogma, pues entre naciones de desarrollo desigual acaba reduciéndose a "lo que es mío así es, y lo que es tuyo es cada vez más mío" (R. Gephardt Dixit).

Por lo que respecta a las exportaciones agropecuarias mexicanas, el café las abandera. Sus ventas están reguladas por una cuota definida en el Acuerdo Internacional del Café. Las exportaciones de café en el periodo 1985-1988 ascendieron a un promedio de 579 millones de dólares, es decir $15 \%$ superiores a las ventas al exterior del resto de los productos tropicales.

Las exportaciones de hortalizas, particularmente de tomate, ajos, berenjenas, brócoli, coliflor, pepinos, espárragos, cebollas así como de algunas frutas como fresas, mango, aguacate y melones, entre otros se han desarrollado exponencialmente en los últimos cinco años por las ventajas comparativas nacionales en el precio de la tierra, la baratísima mano de obra (ver cuadro6), los insumos y, en menor grado la cosecha. Las ventajas en los costos se concentran en las labores anteriores a la cosecha.

Una encuesta realizada por Zepp y Simmons muestra que mientras los costos del cultivo de tomate en 1980 ascendían a 1,113 dólares por acre en la costa de Sinaloa, en California representaban 2,745 dólares (cifra similar a la del sur de Florida), es decir más del doble. En cambio, los costos de las labores de cosecha y sobre todo el empacado y la comercialización eran más altos en Sinaloa que en Florida y California. Esto significa que para seguir ganando mercados habrá que abatir los costos de empaque y mercadeo. 
CUADRO 6. Características de la fuerza de trabajo en tres países en desarrollo

\begin{tabular}{lccc}
\hline & COREA DEL SUR & TAIWÁN & MÉXICO \\
\hline $\begin{array}{l}\text { Costo de una hora- } \\
\text { de trabajo en } 1975^{2}\end{array}$ & $\$ 0.35$ & $\$ 0.39$ & $\$ 2.00$ \\
$\begin{array}{l}\text { Costo de una hora } \\
\text { de trabajo en 1987 }\end{array}$ & $\$ 1.79$ & $\$ 2.19$ & $\$ 1.57$ \\
$\begin{array}{l}\text { Costo del trabajo } \\
\text { manufacturero dia- } \\
\text { rio en 1987 }\end{array}$ & 13.00 & 16.00 & 10.00 \\
$\begin{array}{l}\text { PIB por habitante en } \\
\text { 1970 }\end{array}$ & $\$ 404.00$ & $\$ 686.00$ & $\$ 1274.00$ \\
$\begin{array}{l}\text { PIB por habitante } \\
\text { proyectado para } \\
\text { 1985 }\end{array}$ & $\$ 2368.00$ & $\$ 2304.00$ & $\$ 2075.00$ \\
$\begin{array}{l}\text { Variaciones en el } \\
\text { costo del trabajo en- } \\
\text { tre 1975 y 1987 }\end{array}$ & $14.6 \%$ & $15.5 \%$ & $-2.0 \%$ \\
$\begin{array}{l}\text { Variaciones en el } \\
\text { costo del trabajo en- } \\
\text { tre 1985-1987 }\end{array}$ & $14.7 \%$ & $22.5 \%$ & $-13.3 \%$ \\
$\begin{array}{l}\text { Población enrolada } \\
\text { en educación supe- } \\
\text { rior }\end{array}$ & $26 \%$ & & \\
\hline
\end{tabular}

FUENTE: California Business, diciembre 1988. Sucesos vinculados a la posición agrícola de Estados Unidos y la Comunidad Económica Europea.

1 Se estima una mano de obra mexicana de 15 años o más, de 20 millones para 1980 y una proyección de 42 millones para el año 2000.

2 Dólares norteamericanos.

3 fndice $=1$ dólar $=100$. 


\section{NEGOCIACIONES AGROPECUARIAS EN EL GATT}

Aunque los postulados del GATT teóricamente se aplican por igual a los productos agrícolas que a las manufacturas, la agricultura prácticamente se había mantenido al margen de las negociaciones comerciales. El proteccionismo de los países desarrollados, permitido en el GATT mediante excepciones conocidas como "waivers", los elevados excedentes, la atonía del comercio de productos tropicales, etc., son hechos que durante anfos han obstaculizado el comercio agropecuario. Ahora sus flujos están seriamente distorsionados, paises que eran importadores son exportadores y otros que tienen ventajas naturales para exportar son desplazados del mercado.

El GATT es en el fondo resultado de un proyecto inacabado, que pretendía constituir un organismo internacional del tamaño del Fondo Monetario Internacional o del Banco Mundial, algo así como la Organización del Comercio Internacional (OCI); por lo que surgió un Acuerdo General sobre Comercio más modesto y limitado.

Incluso para que Estados Unidos aceptara la creación del GATT, se aceptó que este país impusiera de entrada tres condiciones en el sector agropecuario: 1) permitir el empleo de restricciones cuantitativas a las importaciones; 2) permitir el uso de subsidios a la importación, y 3) distintas cláusulas de salvaguardia. Con el clima de hegemonía y unilaterismo de Estados Unidos después de las victorias de la segunda guerra mundial, la agricultura prácticamente quedo al margen de las reglas del GATT.

Conviene aclarar que en el Acuerdo General los productos del sector están divididos en tres grupos: el de productos tropicales, el de productos agrícolas, y de recursos naturales donde aparecen los forestales y los pesqueros los cuales tienen características distintas y operan de diferente manera. El Grupo de Productos Tropicales está integrado por siete subgrupos: 1) las bebidas tropicales (café, té, cacao); 2) especies, flores y productos de cestería; 3 ) algunas semillas oleaginosas, aceites vegetales y tortas oleaginosas; 4) raíces tropicales, tabaco y arroz; 5) frutas tropicales y nueces; 6) yute y fibras duras; y 7) caucho natural y maderas tropicales.

Los principales exportadores de productos tropicales son países en desarrollo, donde obtienen buena parte de sus ingresos de divisas. Los principales compradores son paises desarrollados que con frecuencia compran los productos tropicales, los transforman y los regresan a las naciones en desarrollo como productos transformados.

El GATT, particularmente la Ronda de Uruguay, en su Declaración Ministerial de Punta del Este, le confirió gran importancia a las negocia- 
ciones de estos productos por su papel en el desarrollo de las naciones exportadoras, sin embargo, los dos primeros años de la Ronda, no tuvieron mayor impacto por sucesos vinculados a la posición agrícola de Estados Unidos y la Comunidad Económica Europea.

En las negociaciones de Montreal (revisión a medio camino del avance de la Ronda de Uruguay). La CEE trató de aislar a Estados Unidos para evidenciarlo como el saboteador de las discusiones, además orientó su posición a no erosionar las ventajas que le ha otorgado a sus excolonias (los países ACP del Pacto Lomé) y a obtener concesiones de parte de otros países en desarrollo. Ante la inmovilidad de Estados Unidos respecto de su postura inicial de no dar concesiones en tropicales si no había avances en agricultura, la propia CEE redujo su paquete de ofertas.

El Grupo de Agricultura, por otro lado, tiene otra característica, los productos que cubre son los cereales, lácteos y cárnicos (aunque existen acuerdos sectoriales para estos dos últimos grupos de productos), en los cuales los principales exportadores son los desarrollados, mientras que los importadores son países de menor peso en la economía mundial (cuadro 7). Como la sobreoferta de los países avanzados es resultado de la instrumentación de políticas nacionales (subsidios), la corrección de dichas distorsiones, significa cambios a nivel interno sobre los cuales no se pusieron de acuerdo Estados Unidos y la Comunidad Económica Europea.

Finalmente el de recursos naturales está enfrascado en discusiones que bordean el ecologismo y las conexiones que Estados Unidos quiere hacer de los productos forestales y pequeros con los avances que se obtengan en los productos agrícolas.

El nudo de la discusión son los subsidios, pues mientras Estados Unidos propone que se eliminen todos los subsidios para el año 2000, la CEE bólo está dispuesta a negociar los que se relacionan con la exportación. En las negociaciones de Montreal del pasado mes de diciembre, Estados Unidos apoyándose en la baja de los excedentes de 1987 y 1988 y el consecuente aumento de los precios (situación distinta a la que existía cuando se lanzó la Ronda), no estuvo dispuesto a flexibilizar su posición, lo que tampoco hizo la CEE, por lo que no se llegó a ningún acuerdo, más que tratar de lograr algo para el próximo mes de abril. Es evidente entonces que la negociación del comercio agropecuario tiene atorada al resto de las negociaciones.

El grupo Cairns que representa a exportadores "naturales" como Australia, Argentina, Nueva Zelandia, Canadá (entre otros) no logro destrabar las negociaciones, más bien las empantanó. Los países latinoamericanos de Cairns expresaron en una reunión del GruLa (Grupo Latinoamericano) que si no había acuerdo en agricultura no lo habría en el resto de la Ronda; 
CUADRO 7. Principales países importadores de productos agrícolas que pertenecen al GATT

\begin{tabular}{|c|c|c|c|c|c|c|c|}
\hline País & $\begin{array}{l}\text { Agric/PIB } \\
1986 \\
\%\end{array}$ & $\begin{array}{l}\text { E x p o r t } \\
\text { agríc/exp. to } \\
\text { tales } \\
1983-1986\end{array}$ & $\begin{array}{l}\text { I m p ort. } \\
\text { alim/imp. } \\
\text { totales } \\
1983-1986\end{array}$ & $\begin{array}{l}\text { Import. de } \\
\text { cereales } \\
\text { mill/ton. } \\
\text { 1984-1987 }\end{array}$ & $\begin{array}{l}\text { Distribu- } \\
\text { ción } \\
\%\end{array}$ & $\begin{array}{c}\text { Agric. } \\
\% \\
1980-1986\end{array}$ & $\begin{array}{c}\text { Población } \\
\% \\
1986-2000\end{array}$ \\
\hline Japón & 3.0 & 1.3 & 14.7 & 30.4 & 14.7 & 1.0 & 0.5 \\
\hline C.E.E. & 6.5 & 19.0 & 9.9 & 14.3 & 6.9 & 2.6 & 0.6 \\
\hline Egipto & 20.0 & 18.0 & 25.7 & 8.8 & 4.3 & 1.9 & 2.2 \\
\hline Corea & 12.0 & 5.7 & 6.7 & 7.3 & 3.5 & 5.6 & 1.4 \\
\hline México & 9.0 & 13.0 & 15.0 & 6.2 & 3.0 & 2.1 & 2.1 \\
\hline Brasil & 11.0 & 43.0 & 10.7 & 4.6 & 2.2 & 2.0 & 2.0 \\
\hline Polonia & N.D. & 11.0 & 10.0 & 2.4 & 1.2 & N.D. & 6 \\
\hline Marruecos & 3.9 & 28.7 & 16.3 & 2.2 & 1.1 & 3.9 & 2.2 \\
\hline Bangladesh & 47.0 & 30.7 & 23.7 & 2.2 & 1.1 & 2.7 & 2.4 \\
\hline Malasia & 21.0 & 40.0 & 10.0 & 1.6 & .8 & 3.0 & 2.1 \\
\hline Nigeria & 41.0 & 3.5 & 17.7 & 1.5 & .7 & 1.4 & 3.4 \\
\hline
\end{tabular}

FUENTE: Banco Mundial, (Report sur le developpement dans le monde, 1986, 1987 y 1988). FAO. Perspectivas alimenticias, marzo 1988. 
Australia y Nueva Zelandia por su parte se pronunciaron por el logro de acuerdos mínimos o sea de corto plazo, lo que Estados Unidos impugnó.

En consecuencia, los dos años restantes de la Ronda Uruguay no van a ser fáciles. Al parecer Estados Unidos no variará su posición, aunque quizás si lo haga la CEE, sobre todo tomando en cuenta el peso fiscal de su política agrícola. La novedad quizás provenga del grupo de países en desarrollo importadores netos te alimentos, cuya constitución aunque reciente ya comienza a tomar consistencia en posiciones que habrá de fortalecer, proceso en el cual México tiene un papel muy importante.

\section{REPERCUSIONES PARA MÉXICO}

Si bien el país se encamina hacia un nuevo esquema de desarrollo mediante una importante transformación de la estructura productiva que lo haga más moderno y más competitivo frente al exterior, la agricultura ya mostraba desde antes una cierta internacionalización en algunos productos orientados en lo fundamental a la exportación.

El cambio de los ochenta consiste en que esa articulación se realice congruente con otras medidas tendientes a hacer más ordenada la vinculación con el exterior. En estas medidas destaca la racionalización de la protección, el manejo adecuado del tipo de cambio, facilidades crediticias y administrativas, negociaciones en el GATT, búsqueda de nuevos mercados, etc.

La apertura externa ha tenido entre sus propósitos reducir las presiones inflacionarias internas al importar con bajos precios, alentar las exportaciones mediante la eliminación de permisos previos y la baja de aranceles, facilitar las importaciones de insumos (semillas, maquinaria) con la sustitución de permisos previos por aranceles.

Aún es prematuro visualizar los efectos de la apertura comercial (Vidali,. et al. 1988), por el periodo natural que requiere para madurar, pero puede decirse que para que opere plenamente requiere un mayor grado de congruencia en el manejo de otros instrumentos macroeconómicos, en especial del tipo de cambio, determinante tanto de las posibilidades de apertura comercial como para evaluar la retribución y amortización de los factores productivos.

Desde el punto de vista económico no puede esperarse que la apertura siga siendo el instrumento principal para reducir la inflación. La capacidad instalada ociosa, el incremento de las exportaciones sin que se realicen nuevas inversiones y una tasa de cambio subvaluada reemplazaron un tiempo la protección perdida. Por otro lado el proteccionismo de Estados Unidos y la Comunidad Económica Europea impidieron que se alcanzaran 
plenamente los resultados sanos de la política de apertura comercial, al diluir los efectos de una competencia transparente.

El universo de fracciones exentas de licencias previa y las tasas arancelarias vigentes a partir de diciembre de 1987 de un máximo de 20\% (ahora en revisión) muy por debajo de las consolidaciones hechas en el GATT de $50 \%$, son muestras de una apertura comercial sin precedentes. Sólo Chile y México han consolidado un nivel máximo de su arancel, sin paralelo con ninguna otra parte contratante del GATT.

Para fines de 1988 sólo existían 54 fracciones controladas del sector agropecuario. Estas pocas fracciones, sin embargo, representan el $62 \%$ del valor de las importaciones agropecuarias totales, entre las que se encuentran productos básicos de consumo popular como leches, huevos, granos, semillas, oleaginosas, aceites y grasas y café, cacao y tabaco; estos últimos productos son motivo de regulación comercial por medio de órganos especializados (CONASUPO, INMECAFE, CONADECA, TABAMEX) y/o convenios internacionales. Su importancia estratégica vinculada a los principios de soberanía alimentaria, los objetivos del desarrollo rural y el papel del estado como rector de la economía nacional determinaron el mantenimiento del control de estos productos.

Haciendo un balance de las políticas de estabilización de precios y de las medidas de simplificación administrativa es oportuno señalar que ambas afectaron los criterios y propósitos iniciales de racionalización de la protección para el sector agropecuario. Por ejemplo, para garantizar el abasto interno de carne y mantener controlados los precios, se prohibió la exportación de ganado bovino y porcino, de su carne y derivados, haciéndose así a un lado el criterio de protección suficiente a la producción nacional eliminando el arancel de $20 \%$ y permitiendo la libre importación.

Del balance mencionado se derivan varias recomendaciones:

El diseño de políticas macroeconómicas tanto internas como de comercio exterior deben ponderar escrupulosamente las características de la agricultura mexicana y la significativa polarización de los dos subsectores clara y profundamente diferenciados: el comercial y el núcleo campesino.

La Secretaría de Agricultura y Recursos Hidráulicos, responsable de la producción agropecuaria, en su conjunto debe abocarse urgentemente a una investigación profunda sobre las implicaciones sectoriales de la apertura comercial para detectar las áreas críticas que han sido afectadas negativamente y con base en ello preparar los pronunciamientos y propuestas estratégicas específicas para subsanar los eventuales efectos negativos de dicha apertura.

Sobre las fracciones de importación aún bajo control donde destacan maíz, soya, leches en polvo, sorgo, sebo, trigo y frijol, los intentos 
adicionales de mayor liberalización deben ponderar los riesgos de acentuar los desequilibrios estructurales que se pretenden corregir.

Para continuar con el proceso de apertura comercial se requiere de mayor congruencia y consistencia en la instrumentación de la política de racionalización y de una actuación concertada y paralela de las políticas macroeconómicas vinculadas con la producción y la comercialización interna, así como una estrategia definida para la negociación internacional, la bilateral y la multilateral en el GATT. De no ser así, sería más prudente abandonar la idea de abrir la importación agropecuaria básica y olvidarse de los argumentos de que las distorsiones en los precios relativos del sector agropecuario pueden ser corregidos por las fuerzas del mercado. La fijación de topes arancelarios fijos debe flexibilizarse evitando rigideces y superando el sesgo casi doctrinal que hasta ahora ha inspirado el tratamiento de este tema.

La eliminación de los controles cuantitativos en la exportación de productos hortifrutícolas afecta los programas de planeación sectorial para concertar cupos de siembra entre productores y autoridades del sector, con el fin de adecuar la oferta estacional a las condiciones del mercado y garantizar la calidad y la sanidad de los productos exportados. Al respecto, en el sector agropecuario se ha expuesto la tesis de que es necesario el mantenimiento de programas de siembra exportación, en virtud de que nadie sale beneficiado de desórdenes en la oferta de productos caracterizados por su estacionalidad, con excepción del comprador. Sin embargo, se reconoce la necesidad de introducir ajustes en su definición, administración y ejecución, dando mayor apertura a la participación de las organizaciones de productores, mayor eficiencia en los servicios de control y una mayor agresividad en la promoción de mercados externos.

Un hecho que destaca de las ventas sectoriales al exterior es que en su mayoría están conformadas por productos con un proceso de transformación agroindustrial y que han crecido de manera notable en los últimos años, en cambio las importaciones están constituidas por bienes primarios, principalmente cereales, con poco valor agregado. Esta importante diferencia opera a favor de la agroexportación nacional y del proceso de modemización productiva del sector.

La exportación de productos agropecuarios y la transformación agroindustrial de la producción primaria han evidenciado su eficiencia para generar ingresos a los grupos rurales, aunque ciertamente ambas actividades no pueden garantizar por sí mismas un mejor nivel de vida de los campesinos en tanto permanezcan los mecanismos actuales de distribución y apropiación del excedente.

La política nacional de comercio exterior agropecuario debe continuar partiendo del reconocimiento del papel del sector en la economía interna- 
cional, y debe ser regulada y orientada por el interés nacional, armonizando sus repercusiones con el logro de los objetivos del desarrollo rural integral. Estos objetivos, a mi entender, son preservar y consolidar la soberanía alimentaria, elevar el ingreso de los productores rurales y consolidar la capacidad de generar divisas.

Para alcanzar esos objetivos, deben incrementarse las medidas de promoción y fomento a las agroexportaciones de manera diferenciada y por tipo de productor, con base en una tipología que distinga los campesinos productores de granos básicos de los productores ya sea campesinos o empresarios con capacidad para generar excedentes exportables.

La base de las acciones de promoción y fomento de las exportaciones son las organizaciones de productores exportadores, las cuales se deben fortalecer mediante la descentralización y transferencia de funciones del estado a las organizaciones, mediante esquemas que los capaciten para ejecutar los programas y recursos ahora en manos del Estado.

Esto hace necesario apoyar la formación de cuadros técnicos como una forma de favorecer la operación de empresas sociales. El objetivo central debe ser que las organizaciones de productores se fortalezcan y sean capaces de instrumentar con éxito las medidas que las modernicen y hagan eficientes.

La actitud paternalista del Estado tendrá que ir cediendo lugar a una mayor participación de las organizaciones de productores en la toma de decisiones, así como impulsar su incorporación a las repercusiones sobre las posiciones que se sustenten en los organismos internacionales dedicados a la regulación de mercados de productos de interés nacional (Calva, J. Luis:1988).

El principal instrumento para la promoción de las exportaciones es el financiamiento. Se sugiere canalizar de manera eficaz, recursos a la creación de infraestructura productiva, a la importación de insumos y bienes de capital y apoyos para capital de trabajo, acopio, almacenamiento y comercialización externa, con el establecimiento de una adecuada coordinación operativa entre los distintos bancos de tercer, segundo y primer piso que aseguren la eficiencia en el manejo de los fondos crediticios y fomente la competitividad de los productores nacionales en el exterior.

El incremento de la productividad se debe apoyar y estimular mediante acciones que permitan aumentar la oferta exportable y reducir las importaciones. Al mismo tiempo se deberá consolidar y ampliar las exportaciones de productos de probada competencia en el exterior y paralelamente promover la exportación de nuevos productos, sobre todo agroindustrializados en los que las ventajas comparativas permitan perspectivas razonables de exportación. Asimismo habrá que apoyar la creación de agro- 
industrias propiedad de los grupos de productores organizados, prioritariamente para transformar y añadir valor a los productos exportables, como medio de compensar el deterioro de los términos de intercambio y atenuar la vulnerabilidad de los productos perecederos.

La dinámica del comercio hace necesario impulsar la creación de empresas comercializadoras mediante aportaciones financieras y facilidades administrativas y de gestión, así como también será necesario seguir pugnando por la estabilidad de los mercados tradicionales de exportación y emprender esfuerzos por diversificarlos.

La actual concentración de la mayor parte de las agroexportaciones en el mercado norteamericano impone un alto grado de vulnerabilidad a nuestra actividad exportadora. Por lo que en plazo inmediato, la tarea debería dirigirse a asegurar la mayor estabilidad posible para las exportaciones del sector mediante la concertación de acuerdos con nuestro principal socio comercial, orientados a armonizar la aplicación de las normas técnicas, sanitarias y de calidad, que rigen las exportaciones para evitar la aplicación discrecional de barreras al comercio y otras medidas proteccionistas.

La diversificación de mercados habrá de orientarse a las regiones cuyo dinamismo económico ofrecen una expectativa de mercado favorable: la Comunidad Económica Europea, Japón y los demás miembros de la Cuenca del Pacífico y Canadá.

Asimismo habrá de concederse especial importancia a los acuerdos comerciales con los países de América Latina, orientados a consolidar el proceso de integración regional, sobre la base de fórmulas de intercambio no tradicionales.

La instrumentación de la política de fomento de las agroexportaciones tiene como requisito la unidad de mando en las instancias normativas y reguladoras de comercio y la coordinación operativa entre esas y los productores-exportadores, de manera que sus participaciones en los respectivos ámbitos de competencia sean congruentes entre sí y se orienten bajo los mismos propósitos.

La coordinación de la política de agroexportación implica también que las empresas paraestatales vinculadas con el sector respondan a dicho mecanismo de coordinación, de tal forma que los esfuerzos no se dispersen ni se dupliquen y puedan enfrentarse los retos que el desarrollo nacional impone al sector agrícola.

La dependencia de nuestro país de las importaciones de granos básicos, en un mercado internacional en que los flujos comerciales de estos productos se encuentran distorsionados por la aplicación de fuertes subsidios, implica acciones de distinta naturaleza: por una parte, y en tanto no se logre 
la autosuficiencia, el Estado debe continuar controlando las importaciones de granos básicos y de leche, principalmente, a través de los comités participativos de comercialización y la operación de CONASUPO. Al mismo tiempo debe promoverse la sustitución de importaciones para la consolidación de la soberanía alimentaria. Asimismo será importante poner en práctica una estrategia operativa de compras que permita utilizar el poder de compra de las importaciones para negociar mejores condiciones de acceso a las exportaciones.

Respecto a la racionalización, y como se sef́alaba anteriormente, ésta debe acompanfarse de una racionalización en la política de precios para evitar transferencia hacia otros sectores: es necesario proteger mediante permiso previo a los productos básicos fundamentales y garantizar una protección efectiva a las cadenas agroindustriales que quedaron desprotegidas y para los demás alimentos e insumos estratégicos, a fin de evitar competencias desleales del exterior.

Respecto a las negociaciones en el GATT, es necesario adoptar una base de negociación concertada, en particular con países importadores netos de alimentos, que enfrentan problemáticas similares a la nuestra, para acordar con los exportadores las medidas que permitan ampliar y dinamizar los mercados agropecuarios, por la vía de desmantelar los actuales esquemas proteccionistas, dando vigencia al principio de trato especial y más favorable que merecen los países en desarrollo.

Es fundamental adoptar, como estrategia las medidas necesarias para evitar que se utilice al sector agropecuario como "ficha" o elemento de negociación de otros sectores o grupos dentro de la Ronda Uruguay, en congruencia con la prioridad del sector en el desarrollo nacional y de acuerdo con la importancia conferida al sector agropecuario en el Protocolo de Adhesión de México al GATT. Asimismo, habrá que seguir insistiendo en las negociaciones, por convenir así a los intereses de los países en desarrollo.

Como puede apreciarse por lo señalado, tanto respecto a las condiciones externas como internas, el problema de la agricultura mexicana va más allá de las regulaciones sectoriales, es un problema político y de políticas macroeconómicas, que conviene revisar ante el carácter estratégico de la agricultura y la alimentación, de otra manera, sólo se ponen parches que tarde o temprano evidencian sus propias limitaciones y ponen en riesgo la seguridad nacional. 


\section{BIBLIOGRAFíA}

CALVA, J. Luis. 1988. Crisis agricola y alimentaria en México. 19821988. Edit. Fontamara 54. México.

CHIBBARO, Arnaldo. 1988. "Efectos y características de las políticas agrícolas comerciales de los principales países desarrollados sobre el comercio agropecuario internacional". Notas expuestas en la mesa sobre seguridad alimentaria, organizada por la FAO. Santiago, Chile. Mayo 17-20.

DRUCKER, Peter. 1987. "La cambiada economía mundial". Investigación Economica. No. 180. Abril-junio.

FAO. 1988. Perspectivas alimentarias. No. 10, Roma.

LUISELLI, C. y Vidali Carlos. 1989. México en la Ronda Uruguay: el caso de la agricultura. ICA. Enero.

VIDALI, C., et al. 1988. La racionalización de la protección y el comersio exterior agropecuario de México. SARH-ICA. 